\title{
Acessibility in collective housing for the elderly: a case study in Portugal
}

\author{
Paiva, Marie Monique Bruère ${ }^{\mathrm{a}}$ and Villarouco, Vilma ${ }^{\mathrm{b}}$ \\ ${ }^{a}$ Federal University of Pernambuco, PE, Braszil E-mail: mariem.paiva@gmail.com \\ ${ }^{b}$ Federal University of Pernambuco, PE, Braszil E-mail: villarouco@hotmail.com
}

\begin{abstract}
Physical spaces need to be adjusted to suit the changes of a physical, cognitive and emotional order occasioned by the natural aging of people. Ergonomics of the built environment contributes to improving the interaction of the user and physical environment, with a view to their comfort and safety. By thinking through the influence that environments have on the quality of life of the elderly, this article presents an assessment of accessibility in private units - bedrooms and bathrooms - of a Long-Stay Institution for the Elderly (ILPI in Portuguese) in Portugal. The analysis of the physical and spatial conditioning factors by means of the Ergonomics Methodology for the Built Environment (EMBE), proposed by VILLAROUCO (2008), gave evidence of the need for interventions to suitably adapt physical infrastructure, with the objective of promoting the physical well-being of the elderly, and thus, enhancing the autonomy and independence of a wider range of users.
\end{abstract}

Keywords: accessibility, built environment, elderly.

\section{Introduction}

As we age, we face changes of a physical, cognitive and emotional order. Comfortable spaces ones that are adjusted to these restrictions are increasingly required in the built environment, there being, according to Perracini [3], a greater concern with the spatial function serving universal design as opposed to aesthetic form.

To serve those of an advanced age it is necessary to be prepared inside and outside the dwelling, without architectonic barriers, thus promoting individual mobility with full accessibility and the inclusion of the individual. Ergonomics anchored in its interdisciplinarity presents itself as an important tool for studies and projects targeting the elderly, thus allowing greater autonomy, security and comfort. According to VILLAROUCO [5], the purpose of ergonomics of the built environment is to improve the quality of life of users when performing their activities. Thus, the environment is regarded as a fundamental element to serve their functional (physical and cognitive aspects) and formal (psychological) needs.

Knowing that the architecture and design of homes for the elderly influence the quality of life and specialized care they receive [1], institutions for the elderly should display a welcoming ambience with residential features. The physical spaces need to promote, in addition to autonomy, the independence and privacy of the elderly, thus providing for the integration of the users in mixed gender living together among residents with different degrees of disability.

From this perspective, the objective of this article is to analyze the accessibility in individual units - bedrooms and private bathrooms, of a longstay institution for the elderly, by considering safety and comfort key elements for the users' quality of life.

\section{Method}

The case study is exploratory and qualitative in nature, was carried out in an institution located in the town of Vila do Conde, Portugal, and maintained with funds from private, government and philanthropic sources. The building was designed with its own architectonic design to receive elderly people, and built in 1989 using advanced ideas for physical spaces in collective housing.

The focus of ergonomics of the built environment is targeted on human beings as the users of 
space and the suitability of this environment for promoting their safety and well-being. Therefore, to evaluate accessibility in individual units of the Home for the Elderly, use was made of the Ergonomic Methodology for the Build Environment - EMBE, proposed by VILLAROUCO (2008).

The methodology for evaluating the built environment in question uses, while it is being conducted, walk-through techniques, unsystematic and systematic observation, graphic and photographic records, interviews and questionnaires - applied throughout its phases of analysis.

\section{Ergonomic methodology of the built environment - EMBE}

By developing an ergonomic approach so as to understand, evaluate and modify the environment and the continuous interaction with its user, EMBE sets out to examine the environment physically as well as to identify the user's perception of the physical space that he/she experiences. Based on the comparison of the results obtained in the two phases, a diagnosis is generated as are recommendations needed to improve the environment and to make it adequate.

For the ergonomic analysis of the built environment proposed by EMBE, parameters laid down in certain laws are used, such as guidelines, and together with the evaluation of the environmental perception to determine the level of comfort demanded by the user.

In order to better understand the environments, the following describes the EMBE steps adopted for the Home for the Elderly in Vila do Conde.

\subsection{Global analysis of the environment}

The Home for the Elderly is a building designed for the purpose of receiving elderly people. It was inaugurated in 1989 and has a maximum capacity for 175 elderly people. It has air-conditioning in private units for up to three beds with private bathrooms, with the exception of the dormitories for the elderly with a functional disability.

The physical spaces of the institution are bright and pleasant. It is noticeable that it is well organized and kept very clean which confers a sense of the provision of services being taken seriously. Although the flow of personnel in the environments is intense, a high level of noise was not noticed, except in the kitchen (a space with special features) and refectories (a concentration of elderly people).
The structure of the Home for the $3^{\text {rd }}$ Age houses leisure and social spaces - rooms with televisions, with multiple activities, for reading, a library, for games, for dining and a chapel - an area of dormitories and an infrastructure for administration and services. In the building there is also an auditorium and a physiotherapy clinic with independent means of access which offers services to the external community.

The institution serves independent and dependent elderly people in their various degrees, on spontaneous demand (privately) or institutionalized, where to those there privately the alternative is reserved of staying in individual bedrooms, as long as they meet the costs of the private unit.

When the data were collected, the population identified consisted of 157 elderly people, both male and female, of whom the functional capability of 26 elderly patients is preserved and the others have varying degrees of dependence.

The functional staffing of the institution consists of 140 employees including physicians, nurses, caregivers, a nutritionist and staff providing infrastructure services, who periodically take part in training courses and receive an annual functional assessment.

\subsection{Identification of the environmental configuration}

The institution has a total constructed area of $8,041.29 \mathrm{~m}^{2}$ distributed over three floors interconnected by stairs and elevators.

The environments of a common area and leisure, circulation and wet areas have ceramic tile flooring, and the bedrooms have vinyl linoleum. The walls are finished in acrylic paint and the wet areas in ceramic tiling from floor to ceiling. The doors have wood panelling and are compatible for access by a wheelchair user. The windows are in anodized aluminum and double glazed to reduce the thermal and acoustic effect.

Access takes place via a ramp (Figure 1), with a gentle slope and slip resistant flooring, in accordance with Portuguese legislation on accessibility - DecreeLaw 163/2006, and furnished with handrails and guardrails in painted iron, which lead to the entrance hall where the reception and administration work. 


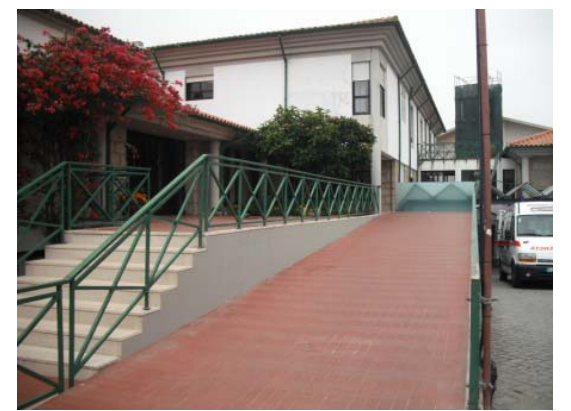

Fig.1: Home for the Elderly in Vila do Conde | Portugal

The typology of the dormitory environments is similar, regardless of the construction phase - initial design or extension - and displays only small differences as to dimensioning.

The rooms have a capacity for 1 (one) bed, 2 (two) beds, 3 (three) beds or 4 (four) beds, in accordance with the dimensioning, and are on three floors of the building. Throughout the building, the circulation areas are equipped with iron hand-rails painted green (Figure 2), emergency and night-watch lighting and vigil, as well as fire-alarm safety devices, and signposting of the escape route for emergencies

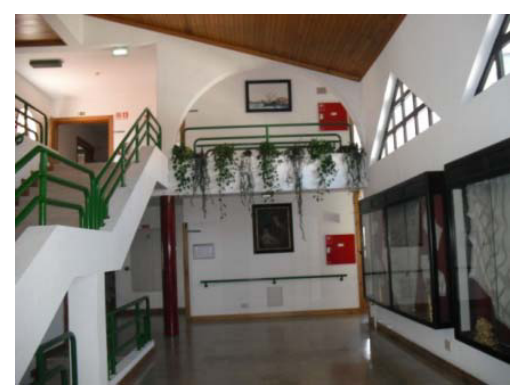

Fig.2: Hall distribution of the bedrooms - Home for the Elderly

Accessibility, free of architectural barriers, is a constant factor in all environments of the Home, which allows users - the elderly and staff - free access to the physical spaces and full independence.

The bathrooms have ceramic sanitary basin of the conventional type and an apparent flush cistern, bidet, column washbasin and bath. In all bathrooms, the doors open from the inside to the environment, contrary to Decree-Law $\mathrm{n}^{0} 163 / 2006$, which lays down in its item 2.9.20, that the access door to general sanitary facilities or accessible cabins should turn or swing to the area external to the environment.

Measurements of the level of luminosity and noise were taken in two distinct situations and compared with those recommended in the legislation. As a result it was found that the level of natural illuminance of the dormitories is above that recommended, while the measurements taken in the bathrooms showed they were below those that are laid down. The circulation paths of the $1^{\text {st }}$ floor - an area reserved for the elderly with impaired functional capacity, and of the $2^{\text {nd }}$ floor - an area reserved for the elderly with some degree of dependence - comply with the legislation and thus match the limits established.

Although there is a concentration of elderly people and a constant flow of people, the noise levels measured comply with the standards laid down, except in the refectory environments at mealtimes and in the kitchen when meals are being prepared.

\subsection{Evaluation of the environment in use}

The biological changes caused by the aging process lead an elderly person to stay longer in their bedroom to rest and sleep [3]. In ILPIs, this permanence also expresses territoriality and privacy for the elderly. The private unit (dormitory and bathroom) represents their residence to the elderly. That is where the user finds his/her identity and keeps his/her references.

This situation has prompted a more detailed study of the accessibility of this environment in search of a better understanding of the physical-spatial conditioning factors that contribute to the greater suitability of the physical spaces and, thus, to preventing unexpected events and accidents.

An important tool for analysing spaces is anthropometry, which by dimensioning investigates the pertinence of the measurements and proportions to serve the needs of the elderly in their various levels of functional capacity.

The dormitories of the institution analyzed present similar characteristics, yet with slight variation in dimensioning due to the construction stage. We detected two typologies of rest units - with and without an entrance hall. All the units are well lit and have a private bathroom equipped with a basin, bathtub or shower, toilet bowl and bidet.

With regard to the formal aspects, the environments of private bedrooms and bathrooms were analyzed in accordance with Portuguese legislation Decree-Law n ${ }^{\circ}$ 163/2006 - Accessibilities and the Normative Despatch $n^{\circ} 12 / 98$ - Norms for the setting up and functioning of Homes, which establish dimensioning and guidelines.

For the analysis of the physical spaces, the possibility was considered of using the environment in a more critical situation, and, therefore, experienced by 
the elderly wheelchair user. Graphic records were used as reference modules that allow the turning cycle of a wheelchair of $360^{\circ}$ and of $90^{\circ}$, represented by the color green, and reference modules that do not allow a turn of $360^{\circ}$ and $90^{\circ}$, represented by the color red.

The unit in the least favorable condition is located on the $2^{\text {nd }}$ floor (Figure 3 ) and belongs to the stage of physical extension of the institution.

The typology of this unit does not display an entrance hall, it being necessary to accommodate space for the wardrobe and for its use, thus reducing the capacity of the environment for two beds.

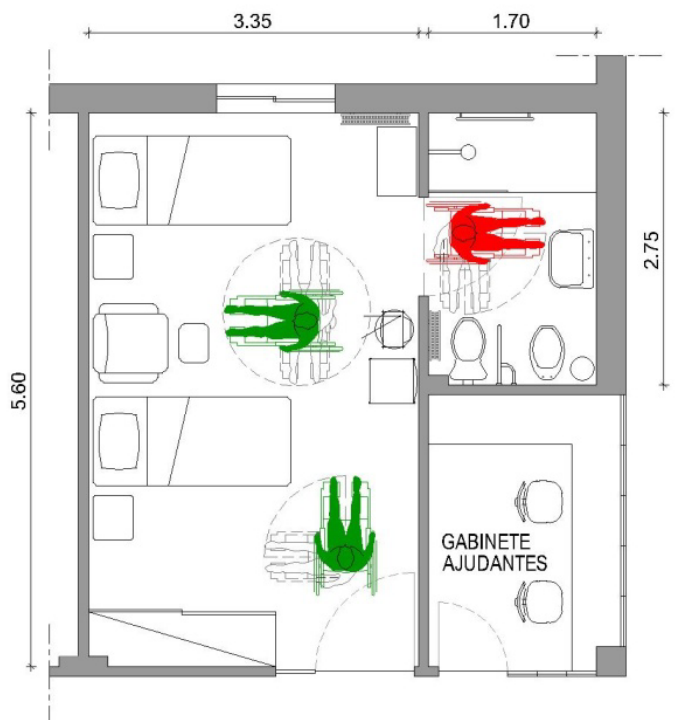

Fig.3: Private unit - $2^{\text {nd }}$ floor Extension Home for the Elderly

The $18.85 \mathrm{~m}^{2}$ physical area of the bedroom meets the dimensioning of $16.00 \mathrm{~m}^{2}$ for double bedrooms, as per DN 12/98, and can accommodate the furniture (Figure 4) in order to provide free access and $360^{\circ}$ manoeuvres for a wheelchair user. As to the furniture, it was observed that the layout identified does not keep the minimum $0.60 \mathrm{~m}$ distance between bed and side wall, required by law.

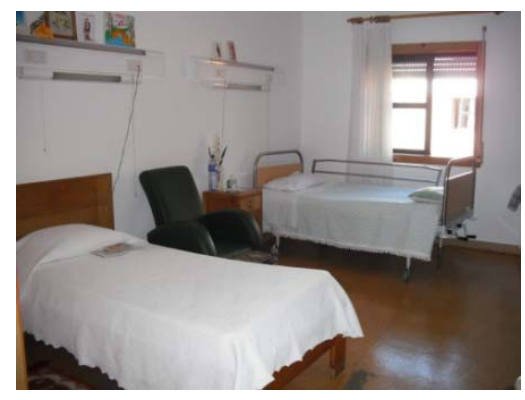

Fig.4: Bedroom $-2^{\text {nd }}$ floor Extension Home for the Elderly.

The dimensioning of the bathroom $\left(4.76 \mathrm{~m}^{2}\right)$ is above the minimum laid down. However, it does not meet the minimum $2.10 \mathrm{~m}$ dimension (Figure 2), in accordance with Portuguese Law 12/98 DN.

The clearance span of the bathroom door allows access by a wheelchair user to the environment. However, it contradicts Decree-Law n ${ }^{\circ} 163 / 2006$ regarding the direction when opening the door, which turns inwards into the bathroom.

The positioning of the sanitary ware and shower presents itself as limiting agents and does not favour appropriate use by people with reduced mobility, nor does it accept a $360^{\circ}$ manoeuvre by wheelchair users. There is restricted access to the toilet bowl as a result of physical constraints (Figure 5) - the heater for the environment and the fixed support bar - which only allows a difficult frontal transfer, and besides being less than $0.45 \mathrm{~m}$ high (DL163/2006). It was observed that there is also an upper cabinet, located above the toilet bowl, which adversely affects the safety of an elderly person and is characterized as an accident risk.

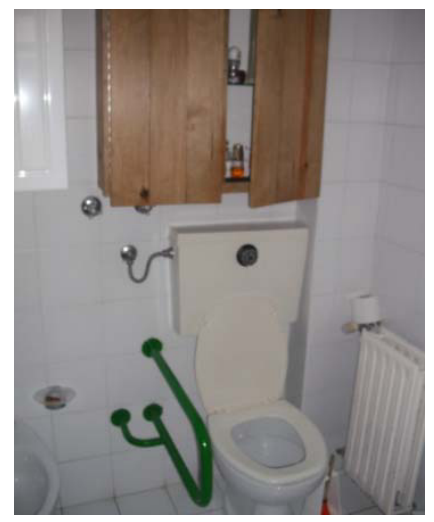

Fig.5: Bathroom - $2^{\text {nd }}$ floor Home for the Elderly. 
The dormitories occupied by three beds have an entrance hall with cupboards for individual belongings (Figure 6), thus ensuring greater privacy for the elderly. The physical area is compatible with laws and spatial accessibility is guaranteed, which allows the wheelchair user access and full movement in the dormitory.

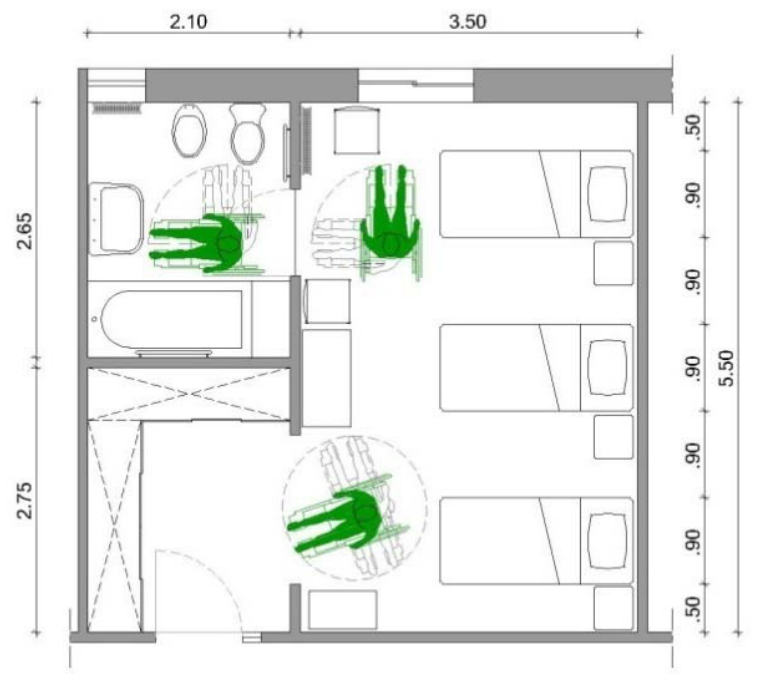

Fig.6: Private unit $-2^{\text {nd }}$ floor Home for the Elderly.

Each bed has its own light and emergency call device connected to the nursing station. Some units have furniture for personal use that fits the environment without disturbing the elderly when they move about (Figure 7).

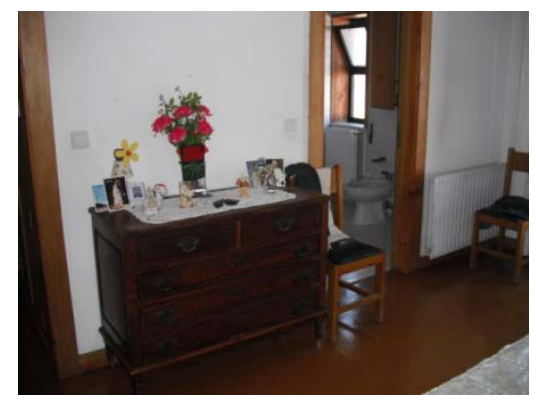

Fig.7: Bedroom - $2^{\text {nd }}$ floor Home for the Elderly.

Although the dimensions of the bathroom are in accordance with the recommendations in Portuguese legislation (DN 12/98), the use of items of sanitary ware and the movement of the elderly wheelchair user are deficient. The wheelchair user is allowed to rotate 90 degrees inside the environment. However, the presence of the bidet does not allow lateral trans- fer to the toilet bowl (Fig. 8). The unit has not undergone reform, like others, and has a bathtub. The use of the wash-hand basin is satisfactory as it permits the approach of a wheelchair.

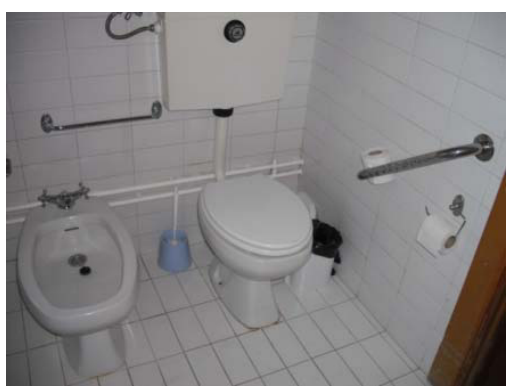

Fig.8: Bathroom - $2^{\text {nd }}$ floor Home for the Elderly.

As with the other bathrooms, the way the door opens is inwards to the environment contrary to DecreeLaw $n^{\circ} 163 / 2006$. With regard to the sanitary ware, the basin and bath are at a lower height than that set out in legislation and the metal fittings, more precisely the taps, are not of the lever type.

\subsection{Environmental perception}

People have their own personalities, different habits and customs. In the elderly these features are exacerbated and, together with the natural losses and impairments of age, affect their way of living and quality of life. The environment exercises fundamental importance because it acts as an agent that facilitates or hinders this quality of life.

Due to the cognitive deficits of the elderly, previous ergonomic studies of the built environment in Brazilian ILPIs [2] indicated that the use of the constellation of attributes can generate a reduction in the reliability of the results obtained in investigations of the perception that the user has of the environment that he has experienced. Thus it was decided to apply a structured questionnaire as a tool of perception, with the characteristics related to environmental perception distributed on a scale of: satisfied, regularly satisfied and dissatisfied represented by figures corresponding to the feeling.

The sample consisted of 15 (fifteen) elderly people, 6 (six) males and 9 (nine) females, whose average length of stay in the institution was 6 (six) years, in an interval ranging from 6 months to 15 years. Of the total interviewed, four of these elderly people have limited locomotion. 
According to the elderly respondents, the place they stay longest in is their bedroom, with 9 (nine) citations, followed by the living room with five (5) citations, and games room with only one. The place they remained longest in is also presented as their favourite place by most of these elderly people.

Regarding the environmental comfort of the spaces in general, all respondents said they were satisfied with the lighting comfort. Most of these elderly people are satisfied with the level of noise of the environments in general, and only 2 (two) said they were regularly satisfied with this. With regard to thermal comfort, twelve (12) of them asserted that they were satisfied and 3 (three) of them regularly satisfied.

With regard to the individual unit (bedroom area), most of these elderly people indicate they are satisfied with the space, size, colors of walls and flooring, lighting, thermal comfort and noise levels. However, only 6 (six) respondents say they are satisfied with the furniture in their bedrooms, and 9 (nine) are regularly satisfied.

Of the total sample of 15 respondents, only 4 (four) of these elderly people claimed to have personal furniture in their rooms - a bed, a head-board table, a chest of drawers and a writing desk.

\section{Conclusion}

The spaces should emphasize the Home as a place of personal and social meaning and be spatially suitable so as to promote the safety and comfort of the elderly person. [4]

The understanding of cognitive and sensory-motor losses caused by the natural process of aging is fundamental to make the built environment suitable for them. The environment is revealed as a facilitator or agent that makes things difficult in accordance with the existing physical and spatial conditions and the perception that the user makes of this space.

Security and autonomy in the elderly maintain a close relationship with suitable environments that contribute to the prevention of unexpected events and accidents. Thus, full accessibility and safety are paramount in physical spaces in the maintenance of the relationship between the user and the built environment and his/her quality of life.

The study looked in more detail at the dormitories and private bathrooms of the elderly, thus seeking a better understanding of the physical-space conditioning factors of the environment, and aiming to broaden the suitability of the space to which users are exposed, which contributes to their physical and mental health.

The analysis of the built environment using the EMBE showed that the bedroom meets the elderly's needs in terms of accessibility and security, this statement being ratified by the users' perception.

However, in the bathroom environment the layout of the sanitary ware gives evidence of restrictions in the area that do not allow full accessibility to the elderly whose physical mobility is temporarily or permanently impaired, in addition to which it may well give rise to unexpected events and accidents.

The results indicate the need for interventions to make the physical infrastructure adequate by replacing bathtubs with shower boxes with folding seats, repositioning the sanitary ware, substituting sanitary metals, and taking other measures, so as to promote the safety and physical well-being of the elderly, thus favoring the autonomy and independence of a greater diversity of users.

\section{References}

[1] Barnes, Sarah and the Design in Caring Environments Study Group. The design of caring environments and the quality of life of older people. Ageing and Society, 22, pp 775-789, 2002.

[2] Leite, Ana Katharina. Avaliação do ambiente construído de instituições de longa permanência para idosos (ILPI). Dissertação de Mestrado. Programa de Pós-Graduação em Design. Universidade Federal de Pernambuco. Recife, 2010.

[3] Perracini, Mônica R. Planejamento e adaptação do ambiente para pessoas idosas. In: FREITAS, Elizabete V., et al. (Orgs.). Tratado de geriatria e gerontologia (pp.1142-1151). Rio de Janeiro: Guanabara, Koogan, 2006.

[4] Tanner, Bronwyn; TILSE, Cheryl; \& JONGE, Desleigh. Restoring and Sustaining Home: The impact of Home Modifications on the Meaning of Home for Older People. Journal of Housing for the Elderly, 22: 3, 195-215, 2008.

[5] VillaroucoI, Vilma. Construindo uma metodologia de avaliação ergonômica do ambiente. In: Anais do XV Congresso Brasileiro de Ergonomia - ABERGO. Porto Seguro - Bahia, 2008 